Psychopharmacology (1985) 85: 377-382

Psychopharmacology

(C) Springer-Verlag 1985

\title{
Effects of morphine, naltrexone, and dextrorphan in untreated and morphine-treated pigeons
}

\author{
Charles P. France and James H. Woods \\ Departments of Psychology and Pharmacology, University of Michigan, Medical School, Ann Arbor, MI 48109, USA
}

\begin{abstract}
Six pigeons, trained to peck a response key on a fixed-ratio 20 schedule of food reinforcement, were used to examine the effects of morphine, naltrexone, and dextrorphan, before, during, and after chronic treatment with increasing doses of morphine (10.0-100.0 $\mathrm{mg} / \mathrm{kg} / \mathrm{day})$. Tolerance developed to the rate-decreasing effect of the daily maintenance doses of morphine within 2 days of each dose increase. A small amount of tolerance to morphine and supersensitivity to naltrexone was evident within the 1st week of morphine treatment $(10.0 \mathrm{mg} / \mathrm{kg} / \mathrm{day})$. Continued administration of morphine $(32.0-100.0 \mathrm{mg} / \mathrm{kg} / \mathrm{day})$ produced further tolerance to morphine and supersensitivity to naltrexone, as evidenced by a 5 -fold increase in the dose of morphine, and 1,000-fold decrease in the dose of naltrexone, necessary to suppress responding. By the 4 th week of treatment $(100.0 \mathrm{mg} / \mathrm{kg} / \mathrm{day})$, a modest tolerance had also developed to the rate-decreasing effects of dextrorphan. Suppression of responding by naltrexone, but not morphine or dextrorphan, was accompanied by a loss in body weight over the 1 - to 2 -h session in morphine-maintained pigeons; both weight loss and reduced response rates also occurred on termination of morphine treatment. Sensitivity to the rate-decreasing effects of morphine and naltrexone was near normal within 10 days following termination of morphine treatment. The dramatic changes in sensitivity to naltrexone and morphine produced by daily morphine injections, as well as the ability to generate complete dose-effect curves within a single session, indicate that this behavioral preparation may provide sensitive concurrent measures of narcotic tolerance and supersensitivity to antagonists in the pigeon.
\end{abstract}

Key words: Morphine - Naltrexone - Dextrorphan Tolerance - Supersensitivity - Pigeons - Operant behavior - Fixed - ratio schedule

The behavioral effects of narcotic agonists and antagonists can vary markedly, depending on the pharmacological and behavioral history of the subject. For example, doses of narcotic antagonists that have no behavioral effects in narcotic-naive animals, can have dramatic effects on behavior in subjects that have received either single (Meyer and Sparber 1977) or multiple (Gellert and Holtzman 1979; Valentino et al. 1983; Villarreal and Karbowski 1974)

Offprint requests to: J. H. Woods injections of narcotic agonists. In pigeons, daily injections of $100.0 \mathrm{mg} / \mathrm{kg}$ morphine have been shown to produce a 300-fold increase in sensitivity to the rate-decreasing effects of naltrexone (Valentino et al. 1983). Conversely, doses of narcotic agonists that suppress schedule-controlled behavior in untreated animals, fail to affect responding significantly in animals that have been treated chronically with a morphinelike compound (Hirschhorn and Rosecrans 1974; McMillan 1974; McMillan and Morse 1967; Woods and Carney 1978).

Tolerance to narcotic agonists and supersensitivity to narcotic antagonists can therefore occur from the same pharmacological treatment (i.e., repeated administration of a morphinelike compound). Supersensitivity to agonists and antagonists can also develop from the prior administration of the antagonist itself (Pert and Snyder 1976; Spealman et al. 1981; Tang and Collins 1978; Zukin et al. 1982); however, this does not appear to be the case in pigeons (Goldberg et al. 1981). The development of tolerance to agonists with chronic administration of morphine has been demonstrated previously (e.g., McMillan and Morse 1967); a quantitative, concurrent comparison of the changes in sensitivity to morphine and naltrexone that result from morphine treatment has, however, not been described in the pigeon.

The purpose of the present study was to examine the changes in sensitivity to the rate-decreasing effects of morphine and naltrexone in pigeons treated chronically with increasing doses of morphine. Stereospecificity of any morphine-induced change was evaluated by periodically assessing the rate-decreasing effects of dextrorphan, the non-opiate dextro-isomer of the narcotic agonist levorphanol (e.g., Herling et al. 1980, 1983). In addition, several days after the termination of morphine treatment, pigeons were again tested with each of the three compounds in order to assess the recovery of normal sensitivity.

\section{Materials and methods}

The subjects used in this experiment were six White Carneaux pigeons maintained at $80 \%$ of their free-feeding weight. The animals were housed individually with water and grit freely available; in addition to mixed grain earned during the experimental session, the reduced body weight was maintained by supplemental feeding (mixed grain and Purina Pigeon Checkers) in the home cage after each session. The subjects were weighed immediately before and after each session. In a previous experiment these subjects had received either phencyclidine or morphine; however, 
they had been maintained drug-free for at least 6 months prior to the present experiment.

Apparatus. Experiments were conducted in ventilated, sound-attenuated chambers measuring $36 \mathrm{~cm}$ high $\times 28 \mathrm{~cm}$ wide $\times 33 \mathrm{~cm}$ long (Ferster and Skinner 1957). Located on one wall, approximately $25 \mathrm{~cm}$ from the chamber floor, were three translucent response keys $(2.4 \mathrm{~cm}$ diameter $)$. In the present experiment, only the center key was used. During food availability the center key was transilluminated red by a 7-W light located behind the key. Responding was maintained by 4-s access to mixed grain made available via a hopper that pivoted into an opening in the wall, directly below the response key. During food presentation the key light was off and a white light illuminated the hopper opening. Control of experimental events, data collection, and recording was accomplished with a Texas Instruments $960 \mathrm{~A}$ computer and cumulative response recorders (Ralph Gerbrands, Arlington, MA) located in a separate room.

Procedure. Experimental sessions were conducted 5-7 days per week. Each session consisted of several discrete trials, each $15 \mathrm{~min}$ in duration. Each trial was preceded by an IM injection of either saline or drug, after which the subject was placed in the experimental chamber for a pretreatment period of $10 \mathrm{~min}$. During this time the chamber was dark and key-peck responses had no experimental consequence. After the 10 -min pretreatment was a 5-min period, during which the response key was illuminated red and a maximum of 10 reinforcements could be earned on a fixed-ratio 20 schedule of food delivery. The trial ended after 10 food presentations or $5 \mathrm{~min}$, whichever occurred first.

Prior to morphine treatment, dose-effect curves were determined for naltrexone, morphine, and dextrorphan. A cumulative dosing procedure was used, whereby increasing doses of a compound were administered prior to each trial. The actual amount of drug administered on each trial, except the first, was the difference (e.g., $2.2 \mathrm{mg} / \mathrm{kg}$ ) between the cumulative dose for that trial (e.g., $3.2 \mathrm{mg} / \mathrm{kg}$ ) and the cumulative dose of the preceding trial (e.g., $1.0 \mathrm{mg} / \mathrm{kg}$ ). All drugs were administered up to doses that suppressed responding completely; each dose-effect determination was preceded by a minimum of six nondrug sessions. On nontest days, pigeons were injected with saline for two or five trials.

Once the initial dose-effect curves had been determined, subjects were treated with increasing doses of morphine and periodically administered naltrexone, morphine, or dextrorphan using the cumulative dosing procedure described above. Daily maintenance doses of morphine were given IM $8 \mathrm{~h}$ before each experimental session, using the following treatment schedule: days $1-7$, $10.0 \mathrm{mg} / \mathrm{kg}$ morphine; days $8-14,32.0 \mathrm{mg} / \mathrm{kg}$ morphine; days $15-21, \quad 100.0 \mathrm{mg} / \mathrm{kg}$ morphine; days $22-27$, $100.0 \mathrm{mg} / \mathrm{kg}$ morphine. Cumulative dose-effect curves were determined for morphine and naltrexone on the 5 th and 7 th day, respectively, of each of the first three treatment periods. In addition, dextrorphan was tested on the second, morphine on the 4th, and naltrexone on the 6th day of the last 6 days of treatment with $100.0 \mathrm{mg} / \mathrm{kg} / \mathrm{day}$ morphine. Finally, the rate-decreasing effects of morphine, naltrex- one, and dextrorphan were redetermined 5, 8, and 11 days, respectively, after termination of morphine treatment.

Drugs. The drugs used in these experiments were naltrexone hydrochloride (Endo Laboratories, Garden City, NY), morphine sulfate (Merck Pharmaceuticals, St. Louis, MO), and dextrorphan tartrate (Hoffmann-La Roche, Nutley, $\mathrm{NJ})$. All drugs were dissolved in $0.9 \%$ sterile saline, and injected IM in a volume of approximately $1 \mathrm{ml} / \mathrm{kg}$ body weight. Doses are expressed in the forms given above.

\section{Results}

Prior to morphine treatment and during saline sessions of five trials, the mean control response rate was $3.44 \pm 0.75$ responses/sec. The mean response rate per trial was: Trial 1 $(\mathrm{T} 1)=3.61 \pm 0.77 ; \mathrm{T} 2=3.56 \pm 0.75 ; \mathrm{T} 3=3.48 \pm 0.72 ; \mathrm{T} 4$ $=3.31 \pm 0.73 ; \mathrm{T} 5=3.22 \pm 0.77$. Expressed as a percentage of the mean saline rate for all six pigeons, these control rates varied from $104.9 \%$ on Trial 1 to $93.6 \%$ on Trial 5 . The consistency of response rates across trials allowed the expression of drug effects relative to the averaged rates of responding across trials.

Naltrexone, morphine, and dextrorphan reduced responding in a dose-dependent fashion to less than $10 \%$ of the saline control rate at doses of $100.0,32.0$, and $10.0 \mathrm{mg} / \mathrm{kg}$, respectively (open symbols, Figs. 1 and 2).

Morphine tolerance. Daily administration of morphine $(10.0-100.0 \mathrm{mg} / \mathrm{kg} / \mathrm{day})$ produced increasing tolerance. After 5 days of treatment with $10.0 \mathrm{mg} / \mathrm{kg}$ morphine, the response-rate dose-effect curve for morphine was altered slightly by intermediate doses, although the dose required to suppress responding to less than $10 \%$ of the control rate was unchanged (Fig. 1a, right panel).

By the 2nd week of morphine treatment $(32.0 \mathrm{mg} / \mathrm{kg} / \mathrm{day})$, the morphine dose-effect curve had shifted approximately $0.75 \mathrm{log}$ units to the right (Fig. 1b, right panel). While responding was markedly suppressed at 56.0 and $100.0 \mathrm{mg} / \mathrm{kg}$ morphine, only a dose of $178.0 \mathrm{mg} / \mathrm{kg}$ reduced the mean response rate to less than $10 \%$ of the saline control rate. Note that in the untreated condition a cumulative dose of $3.2 \mathrm{mg} / \mathrm{kg}$ morphine suppressed responding by approximately $50 \%$; after 7 days of $10.0 \mathrm{mg} / \mathrm{kg}$ and, subsequently, 5 days of $32.0 \mathrm{mg} / \mathrm{kg}$ morphine, $3.2 \mathrm{mg} / \mathrm{kg}$ morphine had no marked effects on responding.

Tolerance to the rate-decreasing effects of morphine continued to increase during the 4th week of morphine treatment, during which time the maintenance dose of morphine was $100.0 \mathrm{mg} / \mathrm{kg} /$ day; however, the dose necessary to suppress responding completely did not increase further (Fig. 1c and d, right panels). Additional tolerance to the rate-decreasing effects of morphine was demonstrated by the total lack of effect of a cumulative dose of $10.0 \mathrm{mg} / \mathrm{kg}$ morphine under this condition, relative to the effects of this dose when given earlier in the study.

Tolerance also developed rapidly to the rate-decreasing effects of the daily maintenance dose of morphine. On the 1st day of treatment at each of the three doses of morphine, responding was suppressed by $18 \%-42 \%$. By the 2 nd day of treatment at each dose, however, response rates had 

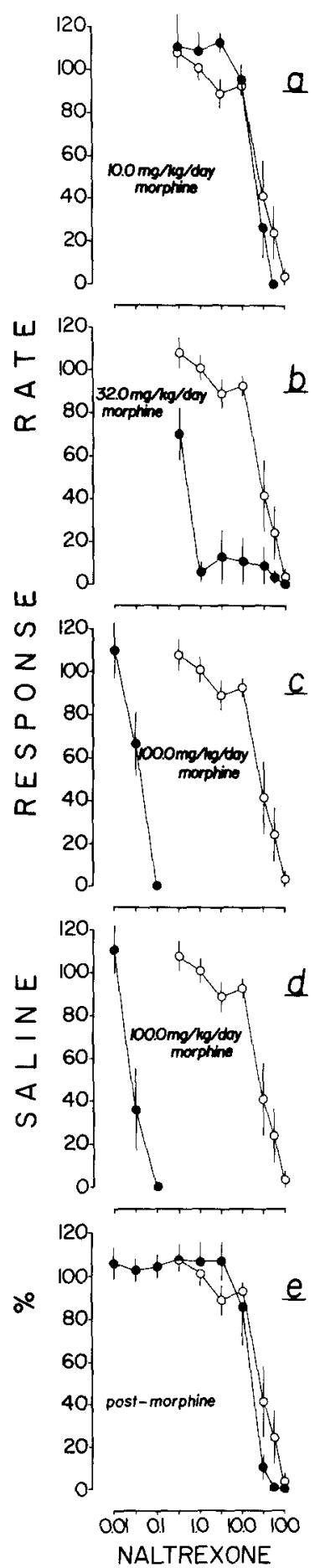

DOSE
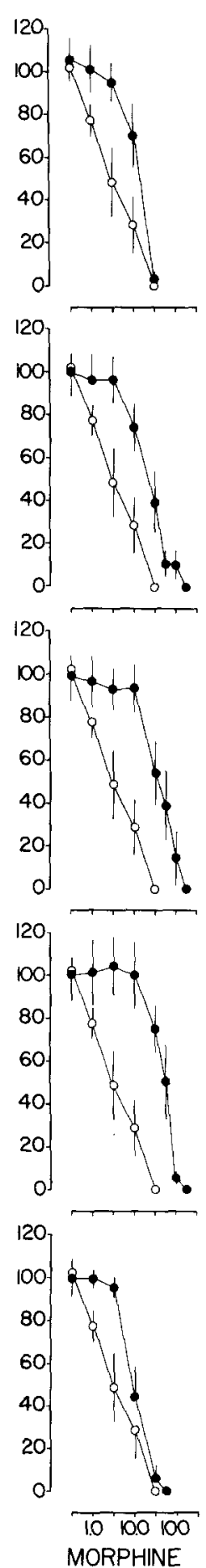

(MG/KG)

Fig. 1. Dose-effect curves for the rate-decreasing effects of cumulative doses of naltrexone (left panels) and morphine (right panels) administered $8 \mathrm{~h}$ after injection of the daily maintenance dose of morphine (a-d) and after termination of morphine treatment (e). a $10.0 \mathrm{mg} / \mathrm{kg} / \mathrm{day}$ morphine; b $32.0 \mathrm{mg} / \mathrm{kg} / \mathrm{day}$ morphine; c $100.0 \mathrm{mg} / \mathrm{kg} /$ day morphine (week 1 ); d $100.0 \mathrm{mg} / \mathrm{kg}$ / day morphine (week 2); e postmorphine treatment. Ordinate: the average response rate for six pigeons, \pm 1 SEM, expressed as a percentage of the saline control response rate over five trials prior to morphine treatment, with each animal serving as its own control. Abscissa: dose of naltrexone or morphine in milligrams per kilogram. The open symbols in each panel represent control dose-effect curves determined prior to morphine treatment

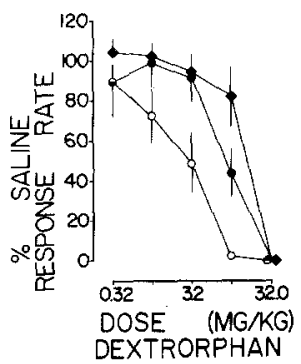

Fig. 2. Dose-effect curves for the rate-decreasing effects of cumulative doses of dextrorphan before, during, and after chronic morphine treatment. Open symbols represent a control dose-effect curve before morphine treatment; dextrorphan was also tested on day 9 of treatment with $100.0 \mathrm{mg} / \mathrm{kg} /$ day morphine (closed circles) and 11 days after termination of morphine treatment (closed diamonds). Other information as in Fig. 1

recovered considerably and were not markedly different from saline control rates.

Naltrexone sensitivity. The naltrexone response-rate dose-effect curve determined on the 7 th day of $10.0 \mathrm{mg} / \mathrm{kg} /$ day morphine was shifted $0.25 \log$ unit to the left, as compared to the control dose-effect curve (Fig. 1a, left panel). In untreated pigeons, a cumulative dose of $100.0 \mathrm{mg} / \mathrm{kg}$ naltrexone suppressed responding completely in five of six pigeons. After treatment with $10.0 \mathrm{mg} / \mathrm{kg}$ morphine, however, all six pigeons were suppressed by a cumulative dose of $56.0 \mathrm{mg} / \mathrm{kg}$ naltrexone.

By the 2nd week of morphine treatment $(32.0 \mathrm{mg} / \mathrm{kg} /$ day $)$, the naltrexone dose-effect curve had shifted to the left by a factor of 100 (Fig. 1b, left panel). A cumulative dose of $1.0 \mathrm{mg} / \mathrm{kg}$ naltrexone decreased the mean response rate to less than $10 \%$ of the control rate, and even the smallest dose tested $(0.32 \mathrm{mg} / \mathrm{kg})$ suppressed responding by $30 \%$. The continuation and partial recovery of the naltrexone dose-effect curve at doses greater than $1.0 \mathrm{mg} / \mathrm{kg}$ is the result of a single subject that continued to respond at these large doses.

As a result of the dramatic shift to the left in the naltrexone dose-effect curve by the 2 nd week of daily morphine treatments, subsequent dose-effect determinations utilized smaller doses of naltrexone. In contrast to the apparent ceiling effect observed for the dose of morphine necessary to suppress responding completely, sensitivity to naltrexone's rate-decreasing effects increased by an additional factor of 10 between the $2 \mathrm{nd}(32.0 \mathrm{mg} / \mathrm{kg} /$ day $)$ and $3 \mathrm{rd}(100.0 \mathrm{mg} / \mathrm{kg} / \mathrm{day})$ weeks of morphine treatment. Thus, when pigeons had been treated with $10.0,32.0$, then 100.0 $\mathrm{mg} / \mathrm{kg} /$ day morphine, the dose of naltrexone necessary to suppress responding completely was $1 / 1,000$ the dose that suppressed untreated pigeons. Pigeons appeared to be slightly more sensitive to the rate-decreasing effects of $0.032 \mathrm{mg} / \mathrm{kg}$ naltrexone during the second week of 100.0 $\mathrm{mg} / \mathrm{kg} /$ day treatment (Fig. 1d, left panel).

Dextrorphan sensitivity. The cumulative dextrorphan dose-effect curve determined on the 9th day of treatment with $100.0 \mathrm{mg} / \mathrm{kg} / \mathrm{day}$ morphine was shifted to the right 0.5 log units relative to the control dose-effect curve (Fig. 2, closed and open circles). In the untreated condition, five of six pigeons were suppressed completely by a cumulative dose of $10.0 \mathrm{mg} / \mathrm{kg}$ dextrophan. During morphine treat- 
ment, this dose of dextrorphan suppressed rates by only $50 \%-60 \%$, and a cumulative dose of $32.0 \mathrm{mg} / \mathrm{kg}$ was necessary to suppress responding completely.

Weight loss and response rates. During chronic morphine treatment, rate suppression produced by cumulative doses of naltrexone was accompanied by a loss in body weight. In the $1 \mathrm{st}$ week of morphine treatment $(10.0 \mathrm{mg} / \mathrm{kg} / \mathrm{day})$ naltrexone produced less than $0.5 \%$ loss of the presession body weight. This contrasts with a greater than $1 \%$ weight gain over a morphine test during the same week. As the daily dose of morphine increased, the amount of weight loss occurring during naltrexone test sessions increased to a maximum loss of $2.16 \pm 0.78 \%$ during the 1 st week of treatment with $100.0 \mathrm{mg} / \mathrm{kg} /$ day morphine. Cumulative doses of morphine or dextrorphan did not produce a consistent weight change during chronic morphine treatment, although an increase in body weight of $1.84 \pm 0.99 \%$ occurred with morphine during the second week of treatment at $100.0 \mathrm{mg} / \mathrm{kg} /$ day morphine.

On the last day of morphine treatment a cumulative dose-effect curve was determined for naltrexone. Over the next $48 \mathrm{~h}$ the mean response rate was markedly reduced, and body weight decreased by an average of $2.97 \pm 0.56 \%$ (i.e., approximately $13 \mathrm{~g}$ ), despite approximately a $50 \%$ increase in the amount of food given in the home cage.

Recovery of drug sensitivity. Upon termination of chronic morphine, the sensitivity of pigeons to the rate-decreasing effects of morphine and naltrexone returned to near normal within several days (Fig. 1e). Five days after termination of chronic morphine, a cumulative dose of $56.0 \mathrm{mg} / \mathrm{kg}$ morphine was necessary to suppress responding completely, although the overall mean rate was less than $10 \%$ of the saline control rate at a cumulative dose of $32.0 \mathrm{mg} / \mathrm{kg}$ morphine (Fig. 1e, right panel). Three days later ( 8 days after termination of morphine), naltrexone sensitivity was redetermined and a cumulative dose of $56.0 \mathrm{mg} / \mathrm{kg}$ suppressed the mean response rate to less than $10 \%$ of the saline control rate, and only a dose of $100.0 \mathrm{mg} / \mathrm{kg}$ suppressed completely in each of the six pigeons (Fig. 1e, left panel). Thus, despite the administration of large doses of morphine on the 5th day after chronic morphine treatment, the sensitivity of these animals to the rate-decreasing effects of naltrexone had recovered almost completely (i.e., shifted to the right by a factor of 560) over a period of 8 days.

Three days after redetermination of the naltrexone dose-effect curve (11 days after termination of morphine), the dextrorphan dose-effect curve remained shifted to the right approximately $0.5 \mathrm{log}$ units (Fig. 2, closed diamonds). Furthermore, a cumulative dose of $10.0 \mathrm{mg} / \mathrm{kg}$ dextrorphan affected responding significantly less after chronic morphine, than had been the case during or before morphine treatment. After morphine treatment, all three compounds produced a small increase in body weight over the test session.

\section{Discussion}

These results clearly demonstrated the dramatic changes in sensitivity to narcotic agonists and antagonists that result from the repeated daily administration of large doses of morphine in pigeons. These data further indicate that enhancement of naltrexone's rate-decreasing effects, and attenuation of morphine's rate-decreasing effects, develop very rapidly and increase in magnitude with the continued administration of morphine. When morphine treatment was terminated, however, the sensitivity of pigeons to the behavioral effects of naltrexone and morphine returned to near normal within several days.

Previous studies have demonstrated the development of tolerance to the rate-suppressing effects of opiate agonists in the pigeon, using a variety of experimental procedures (Heifetz and McMillan 1971; McMillan 1974; McMillan and Morse 1967; McMillan et al. 1971; Woods and Carney 1978). The parameters for inducing tolerance, as well as the persistence of tolerance once morphine treatment is terminated, have not been well documented. While a dose of $10.0 \mathrm{mg} / \mathrm{kg}$ morphine administered once per week was insufficient to produce tolerance to the behavioral depressant effects of morphine (McMillan and Morse 1967; Witkin et al. 1982), if this dose was administered five times per week, significant tolerance developed to the rate-suppressing effects of morphine (McMillan and Morse 1967). The results of the present study confirm the earlier reports in that daily administration of $10.0 \mathrm{mg} / \mathrm{kg}$, for as little as 5 days, resulted in a detectable shift to the right in the morphine dose-effect curve. It is likely, however, that maximal tolerance to $10.0 \mathrm{mg} / \mathrm{kg}$ morphine was not achieved in the present study, since more than 7 days of treatment are necessary to produce maximal tolerance to this dose of morphine (McMillan and Morse 1967; McMillan et al. 1971).

With regard to the morphine maintenance dose, the relative dose dependency of these changing effects of morphine and naltrexone cannot be determined. A fixed dose of morphine administered over the same time period may have produced results similar to those obtained with increasing doses of morphine. The rapid disappearance of tolerance to the rate-decreasing effects of morphine in the present study, after termination of daily morphine injections, was shorter than that reported previously (McMillan et al. 1971). Just as the manifestation of withdrawal signs in narcotic-dependent animals depends upon a number of pharmacological and behavioral variables (Blasig et al. 1973; Gellert and Holtzman 1978), differences in the rates of recovery to the behavioral effects of morphine may be influenced by the frequency and duration of morphine treatment as well as the degree of dependence at the time of morphine termination. Since the animals in the present study were tested with naltrexone on the last day of morphine treatment, the naltrexone may have altered the return to normal weight, food intake, and response rates. Further studies are needed to establish the relationship between maintenance and withdrawal parameters, and the rate of recovery of narcotic dependence and tolerance.

Morphine-treated animals show a dramatic response to doses of narcotic antagonists that have little or no behavioral effects in narcotic-naive animals (Gellert and Holtzman 1979; McMillan et al. 1971; Meyer and Sparber 1977; Valentino et al. 1983; Villarreal and Karbowski 1974; Young and Thompson 1978). Valentino et al. (1980, 1983) showed that doses of naltrexone that produced reliable discriminative control in morphine-treated pigeons were 100-300 times smaller than doses necessary to maintain discriminative effects in narcotic-naive pigeons. Further- 
more, morphine-treated pigeons were approximately 300 times more sensitive to the rate-decreasing effects of naltrexone. The present study extends earlier findings on the behavioral effects of naltrexone in the presence of morphine, and demonstrates the rapid onset and offset of the development of supersensitivity to narcotic antagonists. Furthermore, increased sensitivity to naltrexone in the present study was of a larger magnitude than previously reported for morphine-treated pigeons (Valentino et al. 1983), despite the same maintenance dose of morphine $(100.0 \mathrm{mg} / \mathrm{kg} /$ day $)$. The difference in results may be due to procedural differences.

In morphine-maintained pigeons, administration of naloxone (Young and Thompson 1978) or termination of chronic morphine treatment (Woods and Carney 1978) results in a significant and reliable loss in body weight. In morphine-dependent rats, weight loss is highly correlated with either the administration of a narcotic antagonist or the termination of morphine treatment (e.g., Gellert and Holtzman 1979). While the behavioral signs of opiate withdrawal in the pigeon have not been described, a consistent weight loss occurred in the present study when morphine-treated pigeons were challenged with cumulative doses of naltrexone. Despite approximately a $50 \%$ increase in the amount of food given in the home cage, these animals lost weight upon termination of morphine treatment.

It has been shown that dextrorphan, the non-opiate enantiomer of levorphanol, does not have morphinelike discriminative effects in the pigeon (Jarbe 1978; Herling et al. 1980). Furthermore, in pigeons trained to discriminate dextrorphan from vehicle, naltrexone failed to antagonize the discriminative effects, but antagonized slightly the rate-decreasing effects of dextrorphan (Herling et al. 1983). The antagonism by naltrexone of the rate-decreasing effects of dextrorphan suggests that this action of dextrorphan may, in part, be an opiate effect. Data from the present study support this suggestion, in that tolerance developed to dextrorphan during chronic morphine treatment. However, the interpretation of this result is not clear, due to the lack of recovery of the rate-decreasing effects of dextrorphan after termination of morphine treatment. The relative involvement of opiate mechanisms in the rate-decreasing effects of dextrorphan, therefore, have yet to be assessed adequately.

This experiment demonstrates that marked and rapid changes in sensitivity to the rate-decreasing effects of morphine and naltrexone develop from the repeated daily administration of morphine. The dramatic weight loss and supersensitivity to naltrexone during morphine treatment, as well as the rapid recovery of normal sensitivity to naltrexone, indicate that schedule-controlled responding could be used to characterize the influence of various parameters of narcotic tolerance and dependence in the pigeon. This behavioral preparation may have some advantage over others in that a variety of influences may be expressed in terms of changes in rate of responding. Unlike single dose experiments, the cumulative dosing procedure used in the present experiment allows for the determination of a complete dose-effect curve within a single experimental session. The effects of more than one drug can thus be assessed in the same animal over a relatively short period of time. This procedure, therefore, may be particularly advantageous when studying two dynamic physiological-be- havioral processes, such as opiate tolerance and supersensitivity.

Acknowledgements. This research was supported by U.S. Public Health Service Grant DA 00154. The authors wish to thank Dr. G. Winger for her helpful comments on the manuscript, and Holger Windfuhr for his technical assistance.

\section{References}

Blasig J, Herz A, Reinhold K, Zieglgansberger S (1973) Development of physical dependence on morphine in respect to time and dosage and quantification of the precipitated withdrawal syndrome in rats. Psychopharmacology 33: $19-38$

Ferster CB, Skinner BF (1957) Schedules of reinforcement. Appleton-Century-Crofts, New York

Gellert VF, Holtzman SG (1978) Development and maintenance of morphine tolerance and dependence in the rat by scheduled access to morphine drinking solutions. J Pharmacol Exp Ther $205: 536-546$

Gellert VF, Holtzman SG (1979) Discriminative stimulus effects of naltrexone in the morphine-dependent rat. J Pharmacol Exp Ther 211: 596-605

Goldberg SR, Morse WH, Goldberg DM (1981) Acute and chronic effects of naltrexone and naloxone on schedule-controlled behavior of squirrel monkeys and pigeons. J Pharmacol Exp Ther 216: 500-509

Heifetz SA, McMillan DE (1971) Development of behavioral tolerance to morphine and methadone using the schedule-controlled behavior of the pigeon. Psychopharmacology $19: 40-52$

Herling S, Coale EH Jr, Valentino RJ, Hein DW, Woods JH (1980) Narcotic discrimination in pigeons. J Pharmacol Exp Ther 214: 139-146

Herling S, Solomon RE, Woods JH (1983) Discriminative stimulus effects of dextrorphan in pigeons. J Pharmacol Exp Ther 227: $723-731$

Hirschhorn ID, Rosecrans JA (1974) Morphine and delta-9-tetrahydrocannabinol: tolerance to the stimulus effects. Psychopharmacology $36: 243-253$

Jarbe TUC (1978) Discriminative effects of morphine in the pigeon. Pharmacol Biochem Behav 9: 411-416

McMillan DE (1974) Effects of narcotics and narcotic antagonists on operant behavior. In: Braude MC, Harris LS, May EL, Smith JP, Villarreal JE (eds), Narcotic Antagonists, vol 8. Adv Biochem Pharmacol, Raven Press, New York, pp 345-359

McMillan DE, Morse WH (1967) Some effects of morphine and morphine antagonists on schedule-controlled behavior. J Pharmacol Exp Ther 157:175-184

McMillan DE, Dewey WL, Harris LS (1971) Characteristics of tetrahydrocannabinol tolerance. Ann NY Acad Sci $191: 83-96$

Meyer DR, Sparber SB (1977) Evidence of possible opiate dependence during the behavioral depressant action of a single dose of morphine. Life Sci 21: 1087-1094

Pert CB, Snyder SH (1976) Opiate receptor binding-enhancement by opiate administration in vivo. Biochem Pharmacol $25: 847-853$

Spealman RD, Kelleher RT, Morse WH, Goldberg SR (1981) Supersensitivity to the behavioral effects of opiate antagonists. Psychopharmacol Bull 17:54-56

Tang AH, Collins RJ (1978) Enhanced analgesic effects of morphine after chronic administration of naloxone in the rat. Eur J Pharmacol 47: 473-474

Valentino RJ, Herling S, Woods JH (1980) Discriminative stimulus effects of naltrexone in narcotic-naive and narcoticpretreated pigeons. Pharmacol Biochem Behav 13: 313 
Valentino RJ, Herling S, Woods JH (1983) Discriminative stimulus effects of naltrexone in narcotic-naive and morphine-treated pigeons. J Pharmacol Exp Ther 224: $307-313$

Villarreal JE, Karbowski MG (1974) The actions of narcotic antagonists in morphine-dependent rhesus monkeys. In: Braude MC, Harris LS, May EL, Smith JP, Villarreal JE (eds), Narcotic antagonists, vol 8. Adv Biochem Pharmacol, Raven Press, New York, pp 273-289

Witkin JM, Dykstra LA, Carter RB (1982) Acute tolerance to the discriminative stimulus properties of morphine. Pharmacol Biochem Behav 17: 223-228
Woods JH, Carney J (1978) Narcotic tolerance and operant behavior. In: Behavioral tolerance: Research and treatment implications. NIDA Research Monograph 18, US Government Printing Office, Washington DC, pp 54-66

Young AM, Thompson T (1978) Effects of naloxone on schedule-controlled behavior in morphine-maintained pigeons. J Pharmacol Exp Ther 205:236-245

Zukin RS, Sugarman JR, Fitz-Syage ML, Gardner EL, Zukin SR, Gintzler AR (1982) Naltrexone-induced opiate receptor supersensitivity. Brain Res 245:285-292

Received March 22, 1984; Final version September 25, 1984 